\title{
Simultaneous Bacillus anthracis Spores Detection via Aminated-Poly(vinyl chloride) Coated Piezoelectric Crystal Immunosensor
}

\author{
Ali Oztuna, ${ }^{1}$ Hasan Nazir, ${ }^{2}$ and Mehmet Baysallar ${ }^{3}$ \\ ${ }^{1}$ Department of Medical Genetics, Gulhane Military Medical Academy, 06018 Ankara, Turkey \\ ${ }^{2}$ Department of Chemistry, Science Faculty, Ankara University, 06100 Ankara, Turkey \\ ${ }^{3}$ Department of Medical Microbiology, Gulhane Military Medical Academy, 06018 Ankara, Turkey \\ Correspondence should be addressed to Ali Oztuna; aoztuna@gata.edu.tr and Hasan Nazir; nazir@science.ankara.edu.tr
}

Received 30 May 2014; Accepted 28 July 2014; Published 19 August 2014

Academic Editor: Chao Zhang

Copyright ( 2014 Ali Oztuna et al. This is an open access article distributed under the Creative Commons Attribution License, which permits unrestricted use, distribution, and reproduction in any medium, provided the original work is properly cited.

\begin{abstract}
Bacillus anthracis spores are a potential threat to countries in the context of biodefense. We have already seen the destructiveness of the anthrax attacks in the recent past. This study presents an aminated-poly(vinyl chloride) ( $\left.\mathrm{PVC}-\mathrm{NH}_{2}\right)$ coated quartz crystal microbalance (QCM) immunosensor for simultaneous rapid detection of $B$. anthracis spores. $\mathrm{PVC}^{-\mathrm{NH}_{2}}$, synthesized in the laboratory, was used as an adhesive layer for monoclonal antibody immobilization on gold quartz crystal. The prepared QCM sensor was tested using a pathogen field strain of B. anthracis (GenBank number: GQ375871.1) under static addition and flow through procedures with different spore concentrations. Fourier transform infrared spectroscopy (FTIR-ATR) and scanning electron microscopy (SEM) were performed to characterize the surface of the sensor during the modification. Furthermore, a series of SEM micrographs were taken in order to investigate surface morphology and show the presence of the B. anthracis spores on the surface. It is concluded that $B$. anthracis spores can be accomplished by using amine functionalized polymer coated QCM sensors without requiring complicated immobilization procedures or expensive preliminary preparations.
\end{abstract}

\section{Introduction}

Bacillus anthracis, the etiological agent of anthrax, is a sporeforming bacterium. Dormant spores are highly resistant to adverse conditions including heat, ultraviolet and ionizing radiation, pressure, and chemical agents. They are able to survive for long periods in contaminated soils and thus account for the ecological cycle of the organism. In a suitable environment spores reestablish vegetative growth $[1,2]$. There are three types of human anthrax known: gastrointestinal, cutaneous, and inhalation anthrax. The most dangerous form, inhalational anthrax, results from inhalation of spores aerosolized in sufficiently small particle sizes $(5-10 \mu \mathrm{m})$ to reach the alveoli. The inhalation anthrax is the most severe one because $99 \%$ casualties occurred in individuals who were not treated before symptoms developed [3].

The threat of $B$. anthracis spores as a bioterrorism agent has created an urgent need for a rapid real-time, highly selective, and sensitive technique to detect the presence of anthrax spores. The traditional methods for B. anthracis detection are primarily based on bacteriological, serologyimmunological, and genetic methods [4]. Most of these methods are labouring and time consuming, especially traditional approaches which involve the growing of the microorganism on selective media for at least $24 \mathrm{~h}$ followed by morphological and biochemical analysis [5]. With the developments in the field of science and technology alternative studies, including biosensors, against traditional methods have gained momentum.

After the relationship between the change of resonance frequency of quartz and its mass is shown by Sauerbrey [6], piezoelectric crystals have become one of the most popular transducers used in biorecognition due to their properties such as being cheap and giving rapid and linear response $[7,8]$. To date, QCM immunosensors have been developed to detect pathogenic microorganisms such as Francisella 
tularensis [9], Vibrio cholerae [10], Ebola virus [11], and Influenza virus [12]. However, to the best of our knowledge, there are only two articles related to $B$. anthracis spore detection via QCM immunosensor in the literature. First, Lee et al. [13] used spores of Bacillus subtilis as a nonpathogenic simulant for B. anthracis in their study. In order to immobilize antibodies on the surface they used the self-assembled monolayer (SAM) method. They coated the gold electrode with $3,3^{\prime}$-dithiopropionic acid and subsequently the surface activated with the 1-ethyl-3-(3-dimethylaminopropyl) carbodiimide (EDC) and N-hydrocylsulfo-succinimide (NHS). Also, ethanolamine was used to block unspecific sites on the surface. Required times for all steps have not been stated properly. Authors indicated that prepared immunosensor setup successfully detected the spores and the theoretical lowest detection limit of the immunosensor was 450 spores. Second, Hao et al. [14] used spores of B. anthracis strain A16 in their study and they also prepared their own monoclonal antibodies. They immobilized antibodies on the surface functionalized with mixed SAM and protein A. In order to get mixed SAM they coated the gold electrode with 11-mercaptoundecanoic acid and 6-mercaptohexan-1ol. Subsequently, the surface activated with EDC and NHS. Activated mixed SAM surface was then coated with protein A. Also, bovine serum albumin was used to block unspecific sites on the surface. Total spent time for this method was approximately 31.5 hours. Authors indicated that $B$. anthracis spores and vegetative cells have been simultaneously detected by prepared QCM sensor with success and the theoretical lowest detection limit of the QCM immunosensor was $1 \times 10^{3}$ spores.

Till this time many immobilization methods have been tried with piezoelectric biosensors, but there is still no one ideal method that gives high immobilization yield and good stability. Moreover, the complexity and diversity of biological compounds that can be used for different purposes make it even harder to come up with one optimum method [15]. Therefore, it is necessary to find a suitable immobilization method for each biological material and particular application.

Poly(vinyl chloride) (PVC) is commonly being used as matrix in gas and ion selective sensor applications [16]. On the other hand, PVC as a sensor material might have some certain advantages such as short response time, reproducibility, and simple design when it is made up of functional group (e.g., aminated, carboxylated). In literature, there are not any immunosensor applications among biosensor studies with aminated PVC, while there are some studies in which aminated PVC has been only used for making enzyme immobilization easy [17] or used as a membrane in ion selective electrodes [18]. In this study, we prepared a QCM immunosensor for simultaneous rapid detection of $B$. anthracis spores using PVC- $\mathrm{NH}_{2}$ as an adhesive layer. Meanwhile, we tried to point out that, when an aminated polymer is used as a coating material, complicated immobilization procedures and expensive preliminary preparations will not be required during sensor setup.

\section{Materials and Methods}

2.1. Apparatus. The QCM measurements were carried out in a Model 400A time-resolved EQCM (CH Instrument, USA) linked to a computer equipped with electrochemistry software. The software can record simultaneously $\Delta f-t$. The frequency change, $\Delta f$, is converted into the mass variation, $\Delta m$, through the Sauerbrey equation [6]. Experiments using gold (Au) AT-cut quartz crystal (CHI125A) with a fundamental frequency $7.995 \mathrm{MHz}$ (area $0.205 \mathrm{~cm}^{2}$ ), Teflon detection cell kit (CHI127), and QCM flow cell kit (011121, ALS Co., Ltd., Japan) were performed. At the flow through procedure, in order to get continuous stream of buffer solution ISM831C peristaltic pump with SC0049 tubes (Ismatec, USA) and also to add spores on the buffer stream KDS-100-CE syringe pump (KD Scientific, USA) were used. The elemental analyzer was a varioMICRO CHNS instrument (Elementar Analysensysteme $\mathrm{GmbH}$, Germany). IR spectra were obtained on a Spectrum 100 FTIR spectrophotometer (Perkin Elmer, USA) using ATR in the range of $4000-650 \mathrm{~cm}^{-1} \cdot{ }^{1} \mathrm{H}-\mathrm{NMR}$ spectrum was recorded in dimethyl sulfoxide- $\mathrm{d}_{6}$ on a DPX 400 FT-NMR spectrometer with $\mathrm{SiMe}_{4}$ as internal standard (Bruker, USA). SEM images were recorded on JSM-7000F Field Emission SEM apparatus (JEOL Ltd., Japan).

2.2. Chemicals and Other Materials. Monoclonal antibody (mAb) against B. anthracis spore was obtained from Senova $\mathrm{GmbH}$ (Germany). Schaeffer Fulton stain kit, tryptose agar, plate count agar, 1,3-diaminopropane (1,3-DAP), dimethylformamide (DMF), PVC, phosphate buffered saline (PBS), PBS-Tween 20, and methanol (MeOH) were purchased from Sigma-Aldrich. Geobacillus stearothermophilus spore suspension (Attest 1262 B.I./steam) was purchased from 3M, USA. The deionized water used was generated from a Millipore-Q water system $(18.2 \mathrm{M} \Omega \mathrm{cm})$. All other agents used in this work were analytical grade.

2.3. Synthesis of $\mathrm{PVC}-\mathrm{NH}_{2}$. PVC- $\mathrm{NH}_{2}$ was synthesized in our laboratory by modification of the previously described protocols $[17,19,20]$. PVC $(3.2 \mathrm{~g})$ and 1,3-DAP $(25 \mathrm{~mL})$ were dissolved in $80 \mathrm{~mL}$ of DMF. The mixture was refluxed for $3 \mathrm{~h}$ at $60^{\circ} \mathrm{C}$. After cooling the reaction mixture to room temperature, $15 \mathrm{~mL}$ deionized water was added. Then, the resulting product was washed with $\mathrm{MeOH}$ and was air-dried (Figure 1).

2.4. Preparation of QCM Immunosensor. The quartz crystal was cleaned with fresh piranha solution [conc. $\mathrm{H}_{2} \mathrm{SO}_{4}: 30 \%$ $\mathrm{H}_{2} \mathrm{O}_{2}$ (v/v) was $7: 3$ ] for 20 seconds. Subsequently, the crystal was rinsed with deionized water, followed by drying with $\mathrm{N}_{2}$. After cleaning up, PVC- $\mathrm{NH}_{2}$, which was prepared by dissolving $1 \mathrm{mg}$ PVC- $\mathrm{NH}_{2}$ in $3 \mathrm{~mL}$ DMF, was deposited onto the gold surface of quartz wafer by a drop coating method and allowed for 5 hours in room temperature to get film layer. Then, the crystal was incubated with $0.8 \mathrm{mg} / \mathrm{mL} \mathrm{mAb}$ against B. anthracis spore for $12 \mathrm{~h}$ at $4^{\circ} \mathrm{C}$ (Figure 2). After incubation, it was accepted that all $-\mathrm{NH}_{2}$ groups had reacted with $\mathrm{mAb}$ and a nonspecific binding blocking agent (e.g., bovine serum 


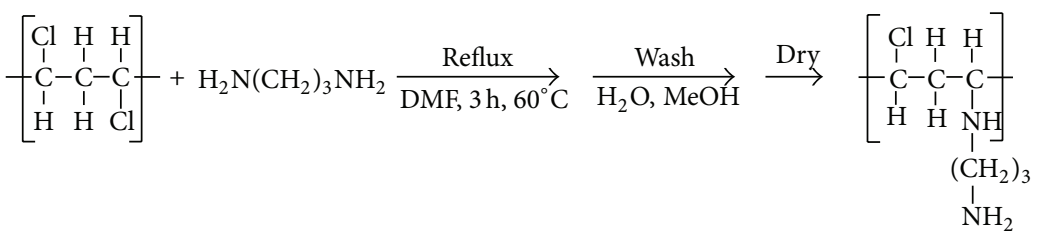

FIGURE 1: Schematic diagram according to synthesis of PVC- $\mathrm{NH}_{2}$.

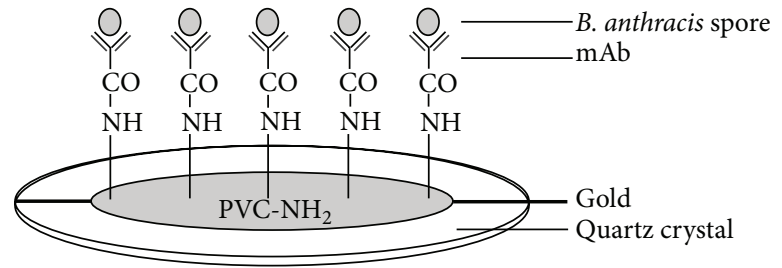

FIGURE 2: Schematic of PVC-NH $\mathrm{N}_{2}$ modified QCM immunosensor.

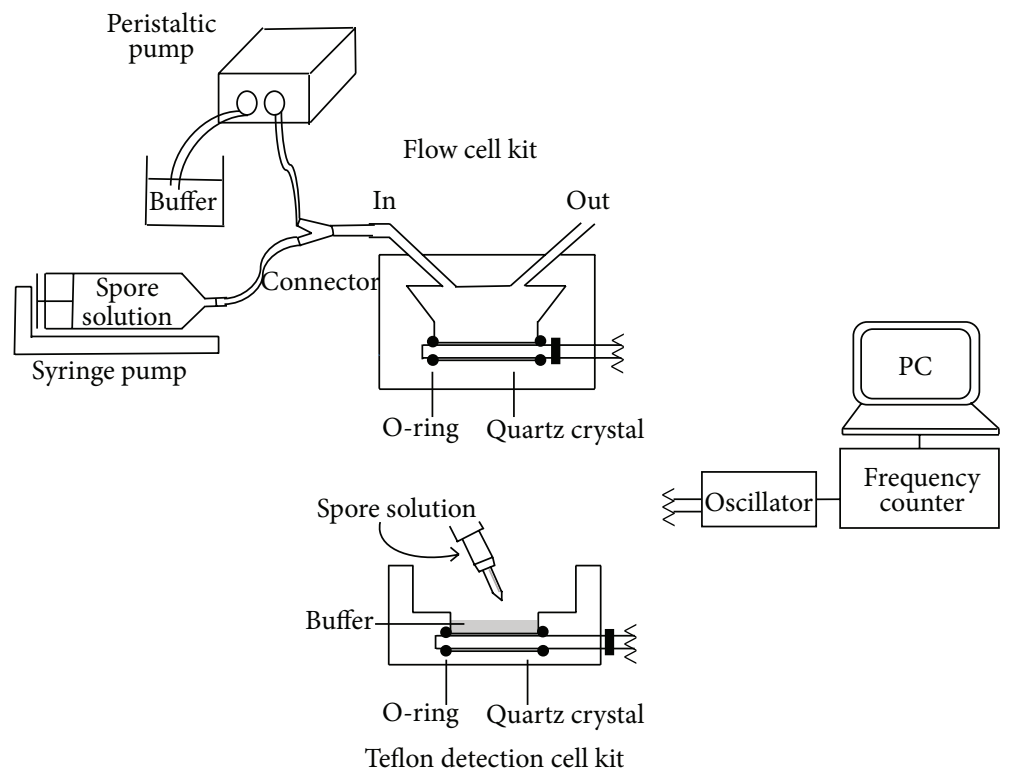

FIGURE 3: Schematic of the experimental setup.

albumin) was not used since there was not any specific groups in PVC which might react with the target.

2.5. Preparation of B. anthracis Spores. For this study a virulent strain of $B$. anthracis, isolated from an outbreak of anthrax which occurred in Turkey, was used for spore production. The pathogenicity of the employed strain, that is, the presence of the pXO1 and pXO2 plasmids, was shown by in-house PCR (the data are not shown here). Furthermore, 16S rRNA gene sequence analysis was performed for identification (GenBank number: GQ375871.1). Preparation of $B$. anthracis spores was done according to the work of Fasanella et al. [21] with slight modifications. B. anthracis was cultured on tryptose agar at $37^{\circ} \mathrm{C}$ for $48 \mathrm{~h}$. Then, it was followed at $23^{\circ} \mathrm{C}$ during 2 weeks. Sporulation was periodically monitored by using the Schaeffer-Fulton method. When sporulation reached $95 \%$, the vegetative organisms were inactivated by incubation with a suspension of $50 \% \mathrm{MeOH}-50 \%$ saline at $37^{\circ} \mathrm{C}$ for $1 \mathrm{~h}$. For $\mathrm{MeOH}$ elimination, spores were washed three times with saline and the pellet was suspended. The number of spore forming units was evaluated by plating 10 fold dilutions in saline onto plate count agar plates which were incubated at $37^{\circ} \mathrm{C}$ for $48 \mathrm{~h}$. Afterward, from a suspension containing about $3 \times 10^{6}$ spore-forming units per $\mathrm{mL}$, dilutions of viable spores were prepared in PBS-Tween 20 on intended concentrations.

2.6. Experimental Procedure. In this study, prepared QCM immunosensor was tested with two different formats, namely, static addition and flow through. A schematic illustration of the experimental setup used in this study is shown in Figure 3. 
At the static addition format, QCM immunosensor was located onto the detection cell kit and one side of the crystal was exposed to $95 \mu \mathrm{L}$ of PBS buffer, pH 7.4. When a state of equilibrium was reached, $5 \mu \mathrm{L}$ of $B$. anthracis spore solution at desired concentration was gently injected into the PBS buffer. Afterward, the frequency shift of the sensor was recorded as a function of time until it reached a stable level.

As distinct from the static addition, continuous stream of PBS buffer solution at $30 \mu \mathrm{L} / \mathrm{min}$ flow rate was injected into the flow cell kit with a peristaltic pump at the flow through format. The role of this continuous buffer stream is to remove unbound and/or nonspecific accumulation of targets near the sensor surface. After the system reached stable level, $B$. anthracis spore solution in different concentrations was injected into the buffer stream at $200 \mu \mathrm{L} / \mathrm{min}$ flow rate with a syringe pump. Finally, the frequency shift of the sensor was recorded as a function of time until it reached a stable level, $1 \mathrm{~Hz} / \mathrm{min}$, again. While testing the specificity of the immunosensor, the same procedure was repeated with the $5 x$ $10^{4}$ spores of G. stearothermophilus.

\section{Results and Discussion}

In order to elucidate the structure of synthesized PVC$\mathrm{NH}_{2}$, FTIR, ${ }^{1} \mathrm{H}-\mathrm{NMR}$ spectra and elemental analysis were examined. The elemental analysis of the final product shows that PVC was $10 \%$ aminated (C, 39.04\%; H, 6.08\%; N, 9.97\%). ${ }^{1} \mathrm{H}-\mathrm{NMR}$ (DMSO-d ${ }_{6}$ ) $\delta$ ppm: 3.54 (broad, $\mathrm{NH}_{2}$ ), 1.48-1.41 $\left(2 \mathrm{H}, \mathrm{C}-\mathrm{C}_{2}-\mathrm{C}, \mathrm{J}_{\mathrm{CH}}=6.72-6.67\right), 2.70\left(4 \mathrm{H}, \mathrm{CH}_{2}-\mathrm{CH} 2-\right.$ $\left.\mathrm{CH}_{2}\right)$. FTIR (neat) (ATR $\left.v \mathrm{~cm}^{-1}\right): 3355,3317\left(\mathrm{NH}_{2}\right), 2973-2911$ $\left(\mathrm{CH}_{2}, \mathrm{CH}\right), 2854-2176$ (intramolecular hydrogen bonds), 1672 (trans $\mathrm{RCH}=\mathrm{CHR}), 1628(\mathrm{R}-\mathrm{CN}-), 1566(\mathrm{NH}), 1487$ $(\mathrm{CH}), 1465\left(\mathrm{CH}_{2}\right)$. The obtained FTIR spectrum, comparatively with PVC, is shown in Figure 4.

FTIR equipped with ATR apparatus can be used to investigate coated surfaces and perhaps it is the most powerful tool to identify the types of functional groups on the surface. By interpreting the infrared spectrum, the functional groups in a molecule can be determined. Therefore, to investigate active $-\mathrm{NH}_{2}$ groups on the quartz crystal surface, FTIR was performed. The results of spectral data are FTIR (ATR $v \mathrm{~cm}^{-1}$ ): $3673\left(\mathrm{NH}, \mathrm{NH}_{2}\right), 3283\left(\mathrm{NH}, \mathrm{NH}_{2}\right), 2972-2920\left(\mathrm{CH}, \mathrm{CH}_{2}\right)$, 1646 (R-CN-) (Figure 5). In addition, SEM micrographs of the crystal surface coated with both PVC- $\mathrm{NH}_{2}$ and $\mathrm{mAb}$ were presented in Figure 6.

It is well known that specific antigen-antibody interactions and sensitivity of the QCM sensor are dependent upon various factors, including roughness of the crystal surface, $\mathrm{pH}$ and the ionic strength, conductivity, and the electric constant of the buffer. Influence of these parameters on the QCM sensor response has already been shown at the previous studies [22-24]. In this study, the influence of these factors was minimized by using the same type of optically polished crystals and using PBS buffer $(\mathrm{pH}$ 7.4) for all of the experiments.

Response of the QCM immunosensor at the static addition procedure for the $2.5 \times 10^{4}$ spore concentration is given in Figure 7(a). As seen in the figure, approximate

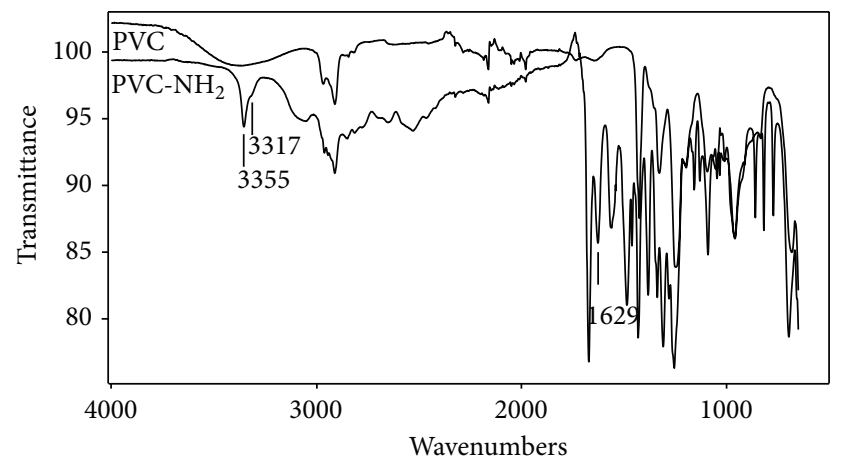

FIGURE 4: Comparative FTIR spectrum of the synthesized PVC$\mathrm{NH}_{2}$.

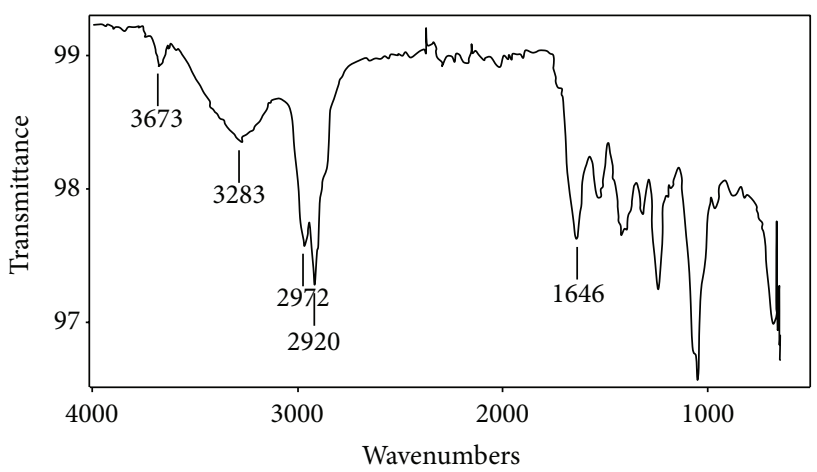

FIGURE 5: FTIR spectrum of the crystal surface coated with PVC$\mathrm{NH}_{2}$.

$\pm 15 \mathrm{~Hz}$ fluctuation around $53 \mathrm{~s}$ is resulted from analyte injection. After frequency shift reached maximum, $-51 \mathrm{~Hz}$, at 690 seconds, system was stabilized around 1450 seconds at $-29 \mathrm{~Hz}$. This $22 \mathrm{~Hz}$ frequency shift appeared probably due to heterogeneous QCM immunosensor surface and nonspecific interactions at the surface-analyte interface.

Flow rate is one of the main factors which affect the frequency change at the flow through procedure. The flow rate of the buffer and target injection is important since the size of spore is too large compared to an antibody. A high flow rate will result in the analytes swept out over sensor surface without having a chance to bind to antibodies. Too slow flow rate will also lead to unnecessary accumulation of unbound analytes near the sensor surface. Certainly, the choice of optimal flow rate depends on the size of the tubes and the type of a flow cell. Features of flow cell-like shape/geometry of reservoir, angle and diameter of inlet-outlet hole have effect on sample dispersion and diffusive mass transport. Because of that, the type of flow cell has an indirect impact on the flow rate. In this study, we determined the flow rate as $30 \mu \mathrm{L} / \mathrm{min}$.

Figure 7(b) represents the response of the QCM immunosensor at three different concentrations of $B$. anthracis spores in flow through format and their calibration curve plot. During the spore injection a small fluctuation occurred, $\pm 5 \mathrm{~Hz}$; afterward, the system reached equilibrium again and stabilized. As seen in the figure, frequency shift 


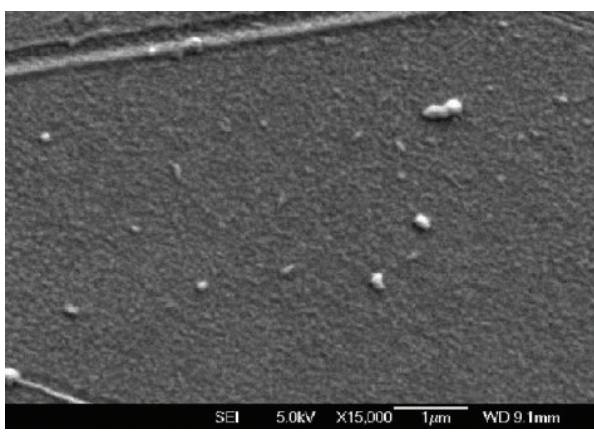

(a)

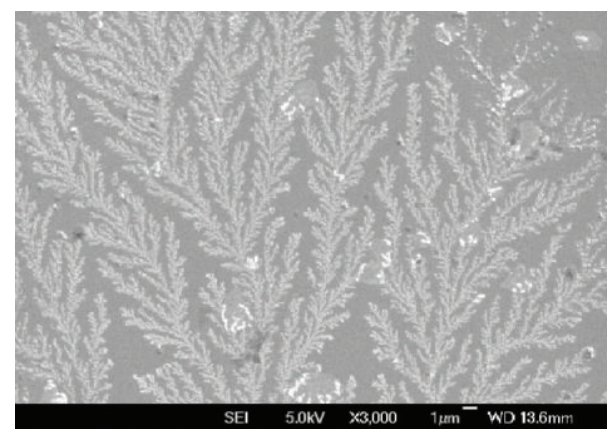

(b)

FIGURE 6: SEM micrographs of the crystal surface coated with PVC- $\mathrm{NH}_{2}$ (a) and PVC- $\mathrm{NH}_{2}$ modified crystal surface coated with mAb (b).

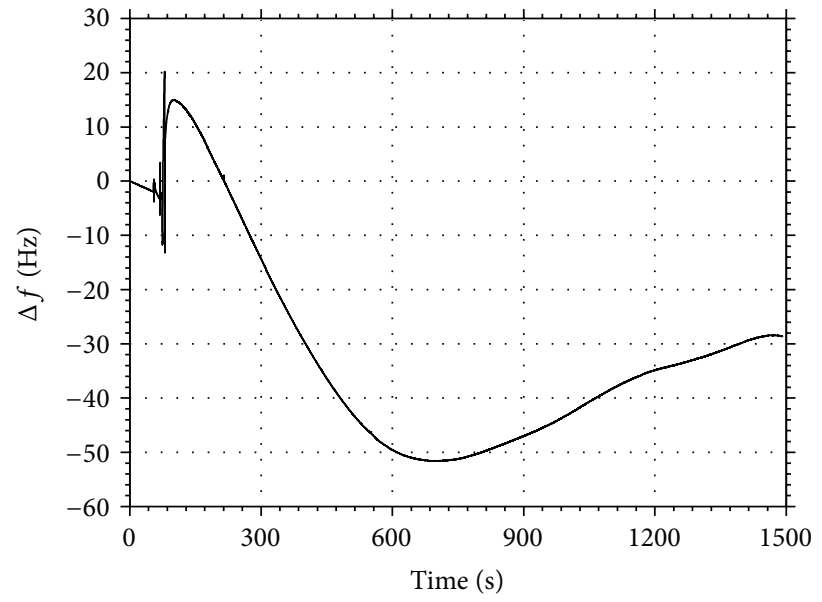

(a)

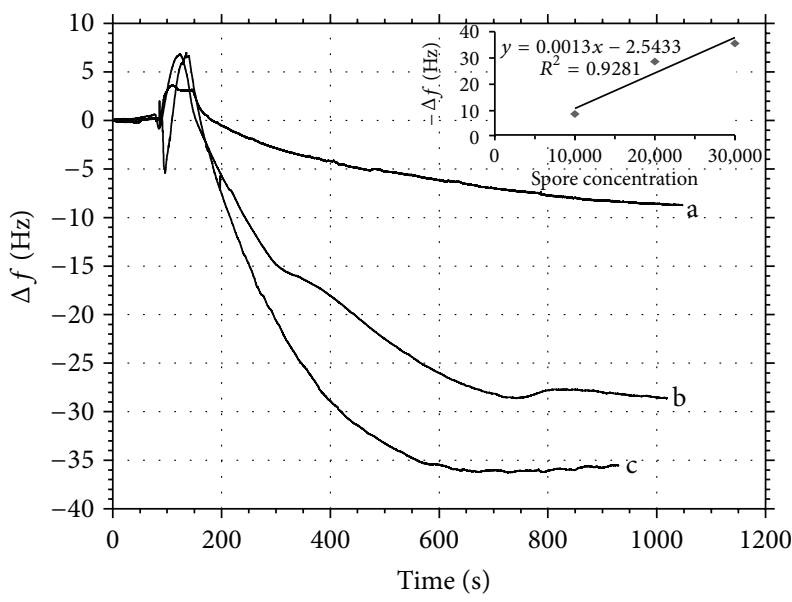

(b)

FIGURE 7: (a) $\Delta f$ - $t$ spectrum of the PVC- $\mathrm{NH}_{2}$ modified QCM immunosensor against $2.5 \times 10^{4}$ spores of $B$. anthracis at static addition procedure (raw data). (b) $\Delta f$ - $t$ spectrum of the PVC- $\mathrm{NH}_{2}$ modified QCM immunosensor against different concentration of $B$. anthracis spores; (a) $1 \times 10^{4}$, (b) $2 \times 10^{4}$, and (c) $3 \times 10^{4}$ spores (raw data) (inset: calibration curve for frequency shift along with concentration).

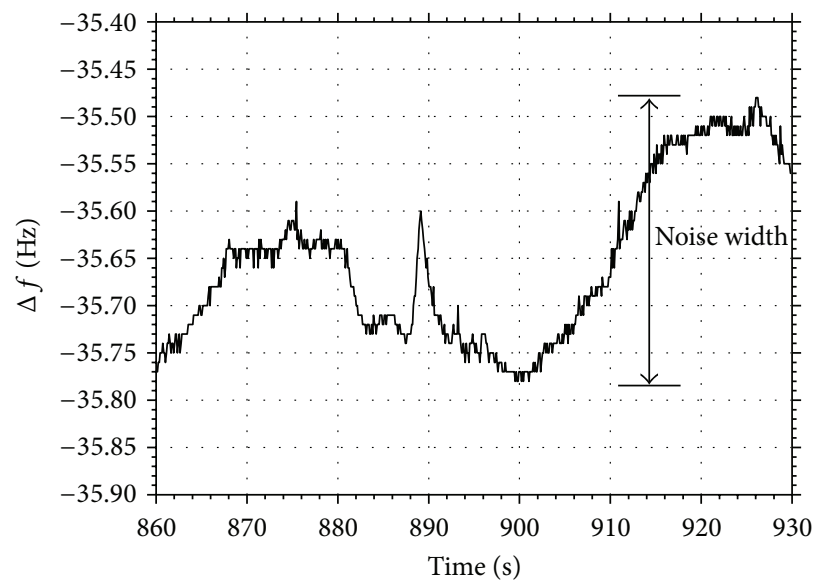

FIGURE 8: Frequency ripples at the system after spore detection and calculation of the noise level of a QCM immunosensor (raw data). 

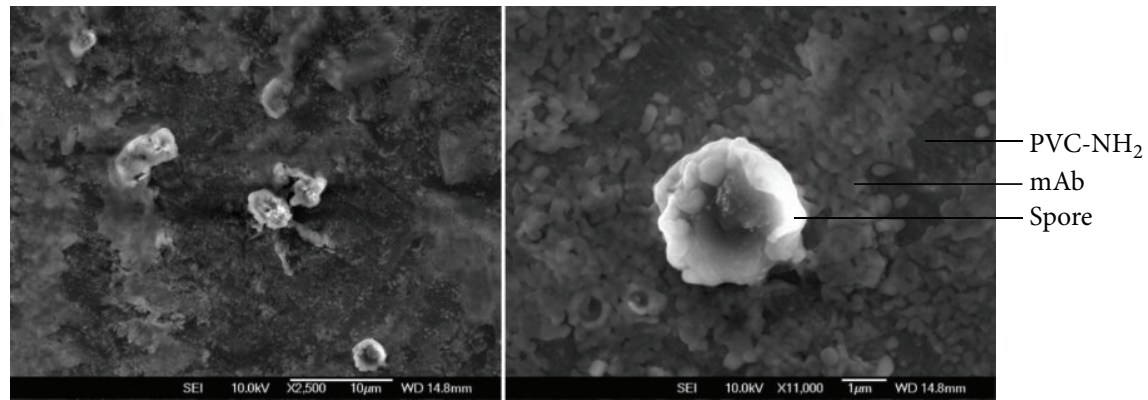

(a)

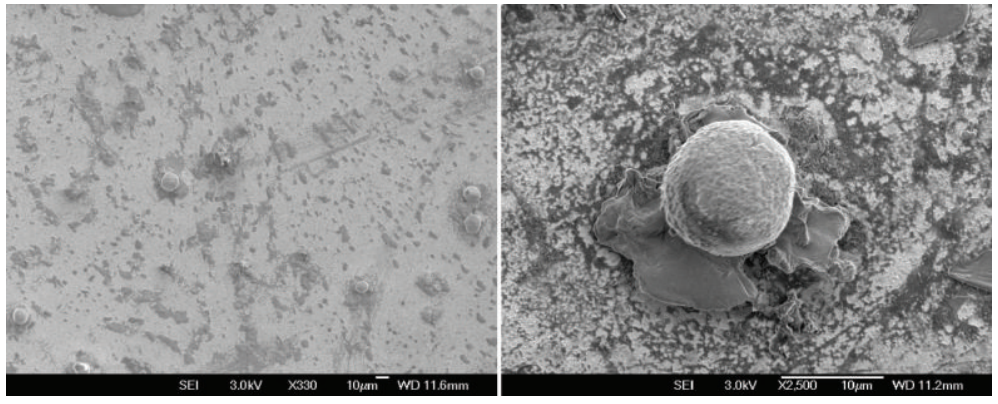

(b)

FIGURE 9: (a) SEM micrographs of the QCM sensor surface after spore detection with static addition. (b) SEM micrographs of the QCM sensor surface after spore detection with flow through format.

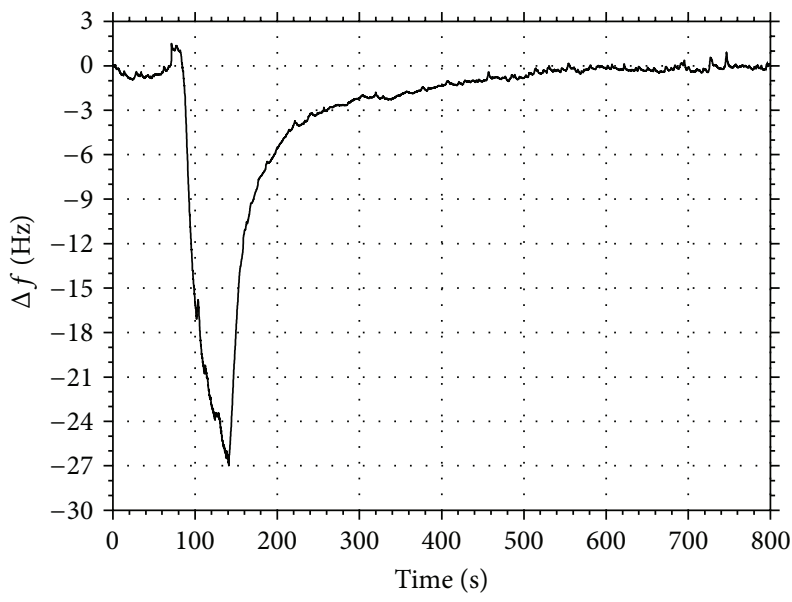

(a)

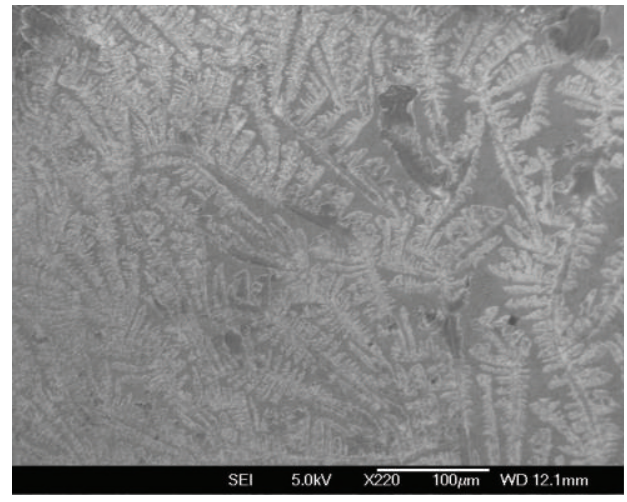

(b)

FIGURE 10: (a) $\Delta f$ - $t$ spectrum of PVC- $\mathrm{NH}_{2}$ modified QCM immunosensor against $5 \times 10^{4}$ spores of $G$. stearothermophilus at flow through format (raw data). (b) SEM micrograph of the QCM sensor surface after experiment with G. stearothermophilus spores.

was increased along with the spore concentration and 8.72, 28.61, and $35.56 \mathrm{~Hz}$ frequency shifts were observed for the 1 $\times 10^{4}, 2 \times 10^{4}$, and $3 \times 10^{4} \mathrm{~B}$. anthracis spores, respectively. However, there were still small frequency ripples at the system. The reason of why these ripples persisted was due to internal noise of system. This internal noise can result from the oscillator, frequency counter, or the mechanical noise of the peristaltic pump. In fact, amplitude of the noise determines the theoretical lowest detection of the sensor [13]. In order to determine the noise level of the prepared
QCM immunosensor, last one minute data of the sensor response given in Figure 7(b) was used. By using the detected noise level, $0.3 \mathrm{~Hz}$, theoretical lowest detection limit of the immunosensor was estimated as 2187 spores [13, 25]. Data related to determined noise level is shown in Figure 8.

After the $B$. anthracis detection experiments, quartz crystals were disconnected from the detection cell and airdried. Then, crystal surfaces were observed by using SEM. Captured spores on the sensor surface can be seen in Figures 9(a) and 9(b). 
In order to evaluate the specificity of the immunosensor, the response of the $\mathrm{mAb}$ functionalized QCM biosensor was tested with the $5 \times 10^{4}$ spores of G. stearothermophilus at the flow through format. The response of the QCM sensor and SEM image of the sensor surface at the end of experiment were shown in Figures 10(a) and 10(b), respectively. During the spore injection, the immunosensor had a negative frequency shift, but frequency turned rapidly to the beginning state and became steady at $1 \mathrm{~Hz}$ after the injection had finished. This was an indication that G. stearothermophilus spores could not be captured on the sensor surface. SEM image of the sensor surface also showed that there was no interaction between the mAb functionalized sensor and the G. stearothermophilus spores.

When experimental results and SEM images are evaluated together it can be said that PVC- $\mathrm{NH}_{2}$ coated surfaces have free amine groups to bind antibody and also interact with $\mathrm{Fc}$ (fragment crystallizable) region of antibody. Therefore, Fab (fragment antigen-binding) regions which will capture spores are functional. Furthermore, PVC- $\mathrm{NH}_{2}$ attaches to the gold surface of the quartz crystal with physical adsorption and covers the whole surface entirely. As a result of these, it can be said that it is possible to use the polymers containing amine functional groups as a coating material in antigen antibody interactions without requiring complicated immobilization procedures or expensive preliminary preparations.

\section{Conclusion}

In this study, an inexpensive and easy setup $\mathrm{PVC}-\mathrm{NH}_{2}$ coated QCM immunosensor was defined for $B$. anthracis spore detection. It was shown that the polymers containing $-\mathrm{NH}_{2}$ functional groups can be used as adhesive layer on sensor surface for antibody immobilization. To simulate the usability of prepared QCM immunosensor in a possible "real-world" situation, a pathogen field strain was used. According to the data obtained from experiments conducted on primates, estimated infective dose for B. anthracis is 8000-50000 spores [26]. Prepared QCM immunosensor was tested under static and flow through methods in the range of infective doses mentioned above and its performance was also close to the previous studies.

\section{Conflict of Interests}

The authors declare that there is no conflict of interests regarding the publication of this paper.

\section{Acknowledgment}

This work was financially supported by the Scientific and Technical Research Council of Turkey (Project no. TBAG108T371).

\section{References}

[1] M. Mock and A. Fouet, "Anthrax," Annual Review of Microbiology, vol. 55, pp. 647-671, 2001.
[2] R. C. Spencer, "Bacillus anthracis," Journal of Clinical Pathology, vol. 56, no. 3, pp. 182-187, 2003.

[3] J. C. Pile, J. D. Malone, E. M. Eitzen, and A. M. Friedlander, "Anthrax as a potential biological warfare agent," Archives of Internal Medicine, vol. 158, no. 5, pp. 429-434, 1998.

[4] K. A. Edwards, H. A. Clancy, and A. J. Baeumner, "Bacillus anthracis: toxicology, epidemiology and current rapiddetection methods," Analytical and Bioanalytical Chemistry, vol. 384, no. 1, pp. 73-84, 2006.

[5] S. S. Iqbal, M. W. Mayo, J. G. Bruno, B. V. Bronk, C. A. Batt, and J. P. Chambers, "A review of molecular recognition technologies for detection of biological threat agents," Biosensors and Bioelectronics, vol. 15, no. 11-12, pp. 549-578, 2000.

[6] G. Sauerbrey, "The use of quartz oscillators for weighing thin layers and for microweighing," Zeitschrift für Physik, vol. 155, no. 2, pp. 206-222, 1959.

[7] C. K. O'Sullivan, R. Vaughan, and G. G. Guilbault, "Piezoelectric immunosensors-theory and applications," Analytical Letters, vol. 32, no. 12, pp. 2353-2377, 1999.

[8] K. R. Rogers, "Principles of affinity-based biosensors," Molecular Biotechnology, vol. 14, no. 2, pp. 109-129, 2000.

[9] M. Pohanka and P. Skládal, "Piezoelectric immunosensor for the direct and rapid detection of Francisella tularensis," Folia Microbiologica, vol. 52, no. 4, pp. 325-330, 2007.

[10] R. M. Carter, J. J. Mekalanos, M. B. Jacobs, G. J. Lubrano, and G. G. Guilbault, "Quartz crystal microbalance detection of Vibrio cholerae O139 serotype," Journal of Immunological Methods, vol. 187, no. 1, pp. 121-125, 1995.

[11] J. S. Yu, H. X. Liao, A. E. Gerdon et al., "Detection of Ebola virus envelope using monoclonal and polyclonal antibodies in ELISA, surface plasmon resonance and a quartz crystal microbalance immunosensor," Journal of Virological Methods, vol. 137, no. 2, pp. 219-228, 2006.

[12] T. W. Owen, R. O. Al-Kaysi, C. J. Bardeen, and Q. Cheng, "Microgravimetric immunosensor for direct detection of aerosolized influenza A virus particles," Sensors and Actuators B: Chemical, vol. 126, no. 2, pp. 691-699, 2007.

[13] S. H. Lee, D. D. Stubbs, J. Cairney, and W. D. Hunt, "Rapid detection of bacterial spores using a quartz crystal microbalance (QCM) immunoassay," IEEE Sensors Journal, vol. 5, no. 4, pp. 737-743, 2005.

[14] R. Hao, D. Wang, X. Zhang et al., "Rapid detection of Bacillus anthracis using monoclonal antibody functionalized QCM sensor," Biosensors and Bioelectronics, vol. 24, no. 5, pp. 1330$1335,2009$.

[15] S. Babacan, P. Pivarnik, S. Letcher, and A. G. Rand, "Evaluation of antibody immobilization methods for piezoelectric biosensor application," Biosensors and Bioelectronics, vol. 15, no. 11-12, pp. 615-621, 2000.

[16] B. Adhikari and S. Majumdar, "Polymers in sensor applications," Progress in Polymer Science, vol. 29, no. 7, pp. 699-766, 2004.

[17] N. Tinkilic, O. Cubuk, and I. Isildak, "Glucose and urea biosensors based on all solid-state PVC- $\mathrm{NH}_{2}$ membrane electrodes," Analytica Chimica Acta, vol. 452, no. 1, pp. 29-34, 2002.

[18] M. Pietrzak, M. Mroczkiewicz, and E. Malinowska, "Application of $\mathrm{F}^{-}$-selective ionophores in carboxylated or aminated poly (vinyl chloride)-based membranes of ion-selective electrodes," Electroanalysis, vol. 24, no. 1, pp. 173-179, 2012.

[19] S. Ma and M. E. Meyerhoff, "Potentiometric $\mathrm{pH}$ response of membranes prepared with various aminated-poly (vinyl chloride) products," Mikrochimica Acta, vol. 100, no. 3-4, pp. 197-208, 1990. 
[20] H. Reinecke and C. Mijangos, "Synthesis and characterization of poly(vinyl chloride)-containing amino groups," Polymer, vol. 38, no. 9, pp. 2291-2294, 1997.

[21] A. Fasanella, S. Losito, R. Adone et al., "PCR assay to detect Bacillus anthracis spores in heat-treated specimens," Journal of Clinical Microbiology, vol. 41, no. 2, pp. 896-899, 2003.

[22] A. Janshoff and C. Steinem, "Quartz crystal microbalance for bioanalytical applications," Sensors Update, vol. 9, no. 1, pp. 313354, 2001.

[23] A. Janshoff, H. J. Galla, and C. Steinem, "Piezoelectric masssensing devices as biosensors-an alternative to optical biosensors?" Angewandte Chemie International Edition, vol. 39, no. 22, pp. 4004-4032, 2000.

[24] N. Kim, I. Park, and D. Kim, "Characteristics of a label-free piezoelectric immunosensor detecting Pseudomonas aeruginosa," Sensors and Actuators B: Chemical, vol. 100, no. 3, pp. 432438, 2004.

[25] R. Scherrer and P. Gerhardt, "Location of calcium within Bacillus spores by electron probe X-ray microanalysis.," Journal of Bacteriology, vol. 112, no. 1, pp. 559-568, 1972.

[26] A. M. Friedlander, S. L. Welkos, M. L. M. Pitt et al., "Postexposure prophylaxis against experimental inhalation anthrax," Journal of Infectious Diseases, vol. 167, no. 5, pp. 1239-1243, 1993. 

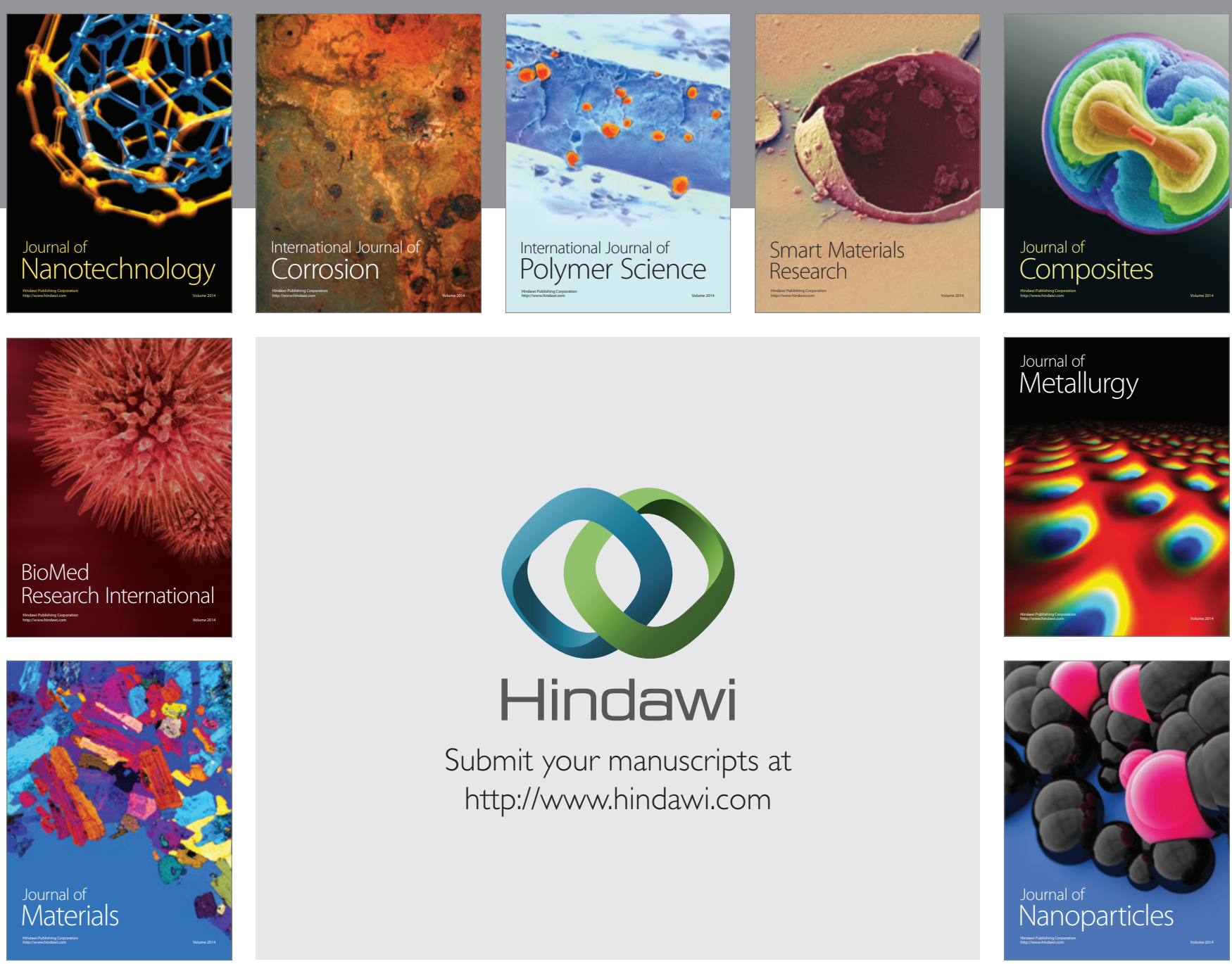

Submit your manuscripts at http://www.hindawi.com
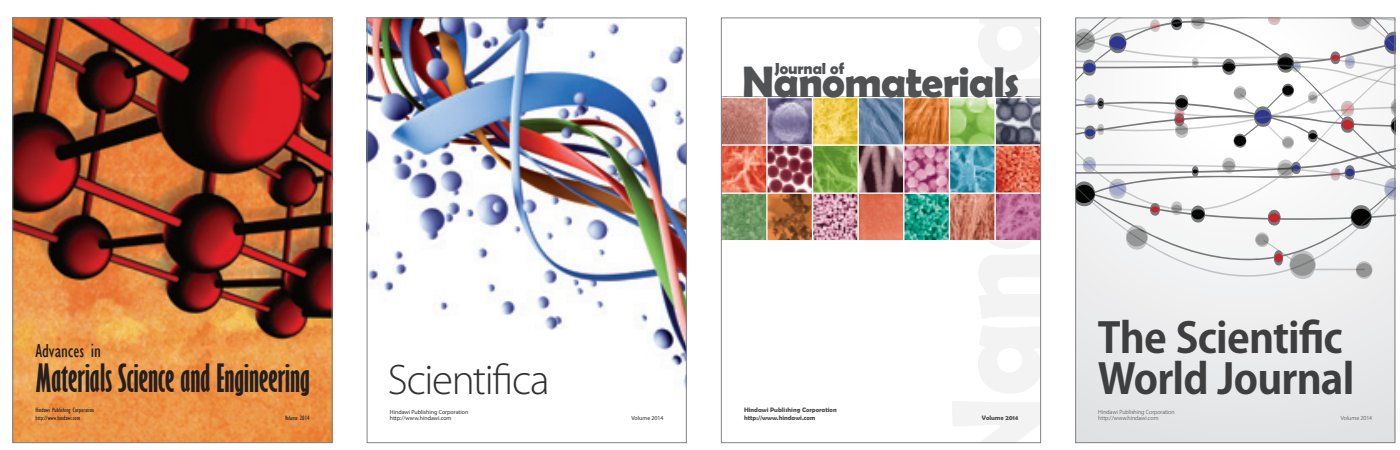

\section{The Scientific World Journal}
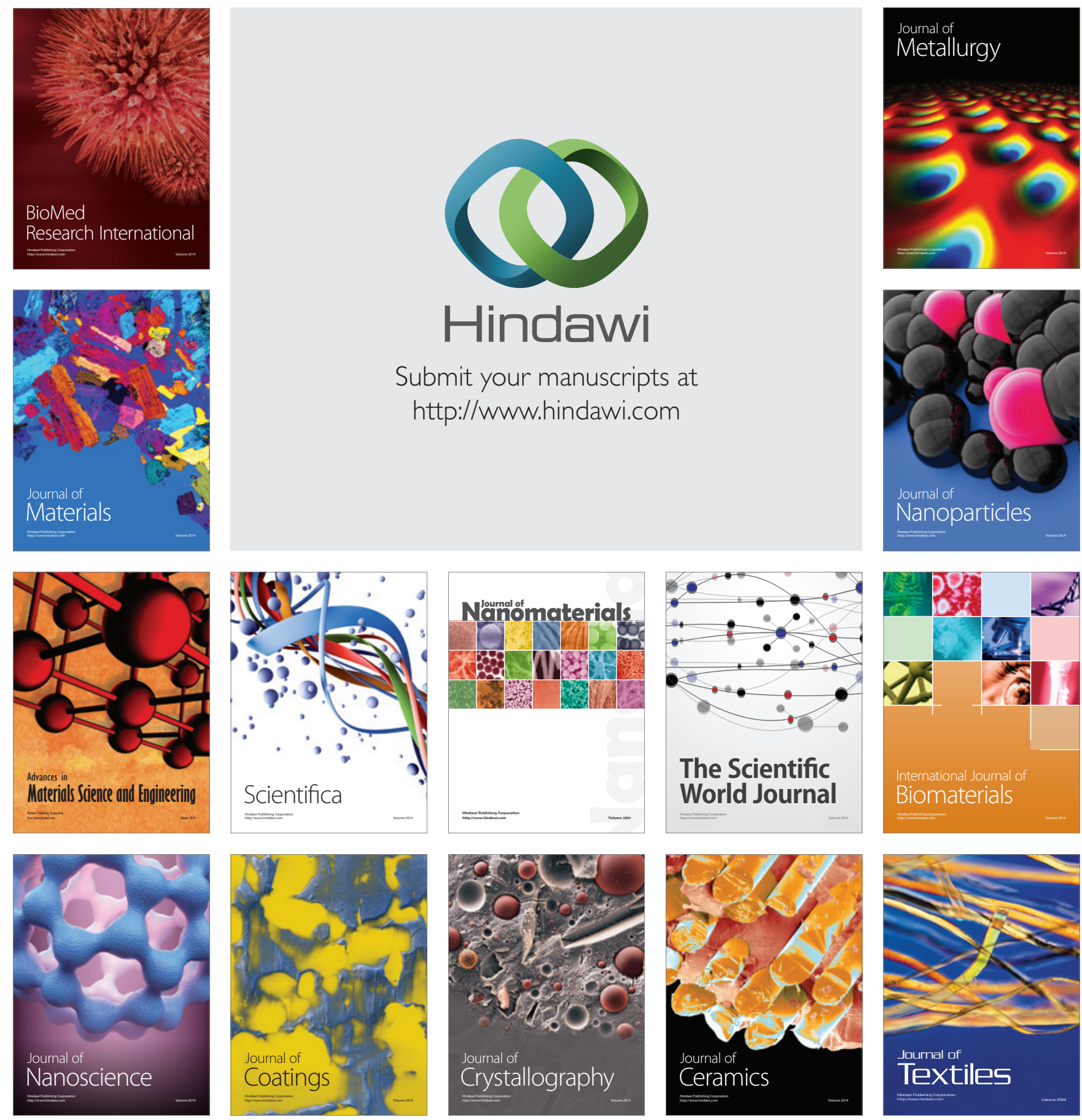